\title{
Estimating Urban Households' Willingness-to-Pay for Upland Forest Restoration in Vietnam
}

\author{
Quy Van Khuc1,2, Mustapha Alhassan33, John B. Loomis', Trung Duc Tran5, \\ Mark W. Paschke ${ }^{1}$ \\ ${ }^{1}$ Department of Forest and Rangeland Stewardship, Colorado State University, Fort Collins, CO, USA \\ ${ }^{2}$ Forestry Economics Research Center, Vietnam Academy of Forest Science, Hanoi, Vietnam \\ ${ }^{3}$ Department of Agricultural Economics, University of Nebraska-Lincoln, Lincoln, NE, USA \\ ${ }^{4}$ Department of Agricultural and Resource Economics, Colorado State University, Fort Collins, CO, USA \\ ${ }^{5}$ Department of Hydrology Meteorology \& Oceanography, Hanoi University of Science, Hanoi, Vietnam \\ Email: mark.paschke@colostate.edu
}

Received 22 April 2016; accepted 29 May 2016; published 2 June 2016

Copyright (C) 2016 by authors and Scientific Research Publishing Inc.

This work is licensed under the Creative Commons Attribution International License (CC BY).

http://creativecommons.org/licenses/by/4.0/

(c) (i) Open Access

\begin{abstract}
Increased urbanization coupled with increased reliance of urban communities on rural areas for ecosystem service provision is a challenge faced by many nations. The ability of urban households to directly support restoration efforts in surrounding rural regions represents an underappreciated funding stream for ecological restoration. This study explored the willingness of urban households to support forest restoration in Vietnam. We surveyed 211 households (HHs) in the capital city Hanoi, Vietnam. A Maximum Likelihood Estimator (MLE) model allowed us to obtain the parameters of our model and quantify mean Willingness-to-Pay (WTP) for a program of forest restoration in addition to identifying factors influencing the decision of WTP. Generally, over forty percent of the households surveyed are willing to pay for forest restoration and the mean value of WTP is 37,830 VND (\$1.73) per household per month. WTP depends on endogenous and exogenous factors including level of education, income, female-to-male ratio in the household, attitude toward payment for monthly electricity consumption, and awareness of payment for environmental service. Our results suggest that urban household's demand for forest restoration is real, and represents an untapped source of restoration funding. Policy-makers should take actions to apply charges on water bills to turn this potential into reality for restoration projects in Vietnam if the benefits from restoration outweigh the costs based on our findings.
\end{abstract}

\section{Keywords}

Willingness-to-Pay, Households, Forest Restoration, U Minh Thuong National Park, Vietnam

How to cite this paper: Khuc, Q. V., Alhassan, M., Loomis, J. B., Tran, T. D., \& Paschke, M. W. (2016). Estimating Urban Households' Willingness-to-Pay for Upland Forest Restoration in Vietnam. Open Journal of Forestry, 6, 191-198. 


\section{Introduction}

Deforestation and forest degradation has become a serious issue in Vietnam, attracting much attention from the government and international organizations. Across 7 ecoregions, the Northwest ecoregion is experiencing one of the highest rates of forest loss and forest degradation (JICA, 2013). Two main reasons are conversion of forests to agriculture via slash-and-burn and illegal logging (Nguyen, 2007). During the 1990s, this region lost thousands of hectares of forest in an area where half was protected for providing water to the Hoa Binh hydroelectric plant (JICA, 2013).

Loss and degradation of protected forests in Northwest Vietnam seriously affects the supply of water and electricity for urban residents and businesses in the lowland including the capital city of Hanoi. The Vietnamese government responded to that issue by enhancing forest protection and rehabilitation programs (De Jong \& Trieu, 2006). However, forest rehabilitation programs have had limited success due to lack of participation from local communities. The underlying reason being that financial support for forest rehabilitation was not sufficient (Sunderlin \& Huynh, 2005).

Associated with this challenging issue, a Payment for Environmental Service (PES) program was piloted in Son La and Lam Dong provinces beginning in 2008 (Nguyen, 2011; Pham et al., 2013). In this PES program, environmental service providers (local households) agreed to protect a certain amount of forest in return for payment from the service buyers (hydroelectric power plants) (Nguyen, 2011). The PES program was successful and effective in terms of attracting local households for forest protection and management (Pham et al., 2013). However, the drawback of this PES program was a long delay in payment to local households (To et al., 2012). Also, there were a limited number of households willing to participate at the low rate of payment (De Jong \& Trieu, 2006). Thus, in this case, mobilizing a source of funding that supports local household participation in forest protection and restoration is imperative.

There have been several studies exploring the potential of payment from society for the conservation and restoration of ecosystems in Vietnam (Do \& Bennett, 2007; Huynh \& Yabe, 2014). In a survey using a singlebounded dichotomous choice question format, Le Hoa \& Lee (2009) found that households in Ho Chi Minh City were willing to pay at least 6209 Vietnamese dollars (VND) per month for three years for the preservation of Lo Go-Xa Mat National Park in Tay Ninh province. Using the same method, Huynh \& Yabe (2014) found that all respondents in Ho Chi Minh city were willing to pay 16,510 VND per household per month for biodiversity conservation in U Minh Thuong National Park (UMTNP). These results suggest that Mekong Delta urban residents have the potential to contribute about 200 billion VND annually for biodiversity conservation in UMTNP. Although these studies have contributed to identifying an untapped source of conservation funding for UMTNP, there is little attention on urban household's WTP for forest restoration in the Northwest upland region of Vietnam.

The objective of our study was to explore the willingness of urban households in Hanoi to pay for forest restoration programs in rural areas of Northwest Vietnam. Our overall goal was to estimate how large of an untapped resource the urban population was for supporting forest restoration in the upland area.

\section{Methods}

\subsection{Contingent Valuation Method}

Contingent Valuation Method (CVM) is a survey-based approach for finding values people place on goods, services, and amenities (Boyle, 2003). The CVM is a simple, flexible nonmarket valuation method that is widely used in cost-benefit analysis and environmental services (Reutterer \& Breidert, 2007; Khuc, 2013). It requires individuals to state their preferences through their responses to specific WTP questions (Boyle, 2003).

Three main CVM response formats are open-ended, payment card and dichotomous and each of these response formats has its own strengths and weaknesses. While an open-end format often results in overestimating WTP, dichotomous-choice WTP questions only obtain a limited amount of information from each respondent. The payment card method is a question format in which the respondents are asked to pick a WTP point estimate from a list of values predetermined by the surveyors. The payment-card and multiple-bounded response formats are advantageous as they provide more information per respondent (Boyle, 2003). Another advantage of payment card method is that it is simpler than open-ended format, so larger range of responses could be obtained. 
However, this method requires the interviewees to be literate (Yalfal et al., 2013). The urban residents in Hanoi met this requirement. Therefore, in this study we used a payment-card method. A survey questionnaire was designed to follow previous studies (Boyle, 2003; Alhassan 2012). For the survey used in this study, face-to-face interviews were used since this method allowed the study team to obtain data during a short time period with high response rate, which other methods such as email, phone, and mailings would be inferior at.

\subsection{The Empirical Model}

In this study we used a payment card method following the procedure of Boyle (2003). Specifically, in a payment card survey, each respondent is confronted with a series of money amounts, and asked to circle their maximum WTP for forest restoration. The respondents were also given the option of indicating "zero" for WTP.

Following Cameron and Huppert (1998), Boyle (2003) and Alhassan (2012) the payment card data was analyzed by modeling the intervals that are bounded by the bid amounts the respondent circled and the next highest amount on the payment card. The payment level, $\left(Y_{i}\right)$ lies within the interval defined by lower and upper thresholds $t_{1 i}$ and $t_{u i}$, so $\left(\log Y_{i}\right)$ lies between $\left(\log t_{1 i}\right)$ and $\left(\log t_{u i}\right)$. The $E\left(\log Y_{i} \mid x_{i}\right)$ is the function of $g\left(x_{i}, \beta\right)$. Where $x_{i}$ is the vector of the independent variables of respondent and $\beta$ is the vector of the coefficients estimated. $\beta$ is estimated from the following function of the simplest case:

$$
\left(\log Y_{i}\right)=x_{i}^{\prime} \beta+u_{i}
$$

where $u_{i}$ is the random error term assumed to be distributed normally with mean, 0 and standard error, $\sigma$. Each pair of interval thresholds for $\left(\log Y_{i}\right)$ is standardized and expressed by the following formula:

$$
\operatorname{Pr} Y_{i} \subseteq\left(t_{i i}, t_{u i}\right)=\operatorname{Pr}\left(\left(\log t_{1 i}-x_{i}^{\prime} \beta\right) / \sigma<Z_{i}<\left(\log t_{u i}-x_{i}^{\prime} \beta\right) / \sigma\right)
$$

where $Z_{i}$ is the standard normal random variable. Equation (2) can be re-written as $\Phi\left(Z_{u i}\right)-\Phi\left(Z_{1 i}\right)$, where $\Phi$ is the cumulative standard normal density function, $Z_{u i}$ and $Z_{1 i}$ present the lower and upper limits. For $\mathrm{n}$ independent observations, the joint probability density function can be interpreted as a likelihood function defined over the unknown parameters, $\beta$ and $\sigma$. The log-likelihood function is expressed by the following formula:

$$
\log L=\sum_{i=1}^{n} \log \left[\Phi\left(Z_{u i}\right)-\Phi\left(Z_{1 i}\right)\right]
$$

Next, Maximum likelihood estimation (MLE) procedure was used to estimate the Equation (3). The mean and the median WTP was calculated by constructing the fitted values of $\log Y_{i}$ after regression. $\log Y_{i}$ is transformed into $Y$ representing the median WTP value. Finally, the mean WTP was the product of the median WTP and $\exp \left(\frac{\sigma^{2}}{2}\right)$.

\subsection{Study Area}

Deforestation and forest degradation in Northwest Vietnam has impact on the quantity and quality of water and electricity provided downstream to the Hanoi metropolitan area (Bishop \& Landell-Mills 2002; Nguyen \& Tenhunen, 2013). Hanoi is not only the capital but also one of the largest cities in Vietnam. Thus, Hanoi was selected as the survey population. A total of $220 \mathrm{HHs}$ were chosen randomly to contact for an interview in two areas, Hoang Mai and Thanh Xuan districts, where the residents had been being affected by a lack of water and electricity in recent dry years. Table 1 presents main characteristics of respondent of the survey in terms of gender, age, education, household's gender structure, and gross household income.

\subsection{Data Collection}

The investigation was conducted in November 2014.First of all, a focus group of 8 people, who are seniors in 
Table 1. Characteristics of 211 urban respondents and their households (HHs) from a survey of willingness-to-pay for upland forest restoration in Vietnam. Family income is presented in millions of Vietnamese dollars (MVND).

\begin{tabular}{|c|c|c|c|c|c|}
\hline Characteristics & (HHs) & $(\%)$ & Characteristics & (HHs) & (\%) \\
\hline$\underline{\text { Gender of HHs head }}$ & & & Education of HHs head & & \\
\hline Male & 77 & 36.5 & No formal education & 17 & 8.1 \\
\hline Female & 134 & 63.5 & Under 5 & 9 & 4.3 \\
\hline Age & & & $6-9$ & 38 & 18.0 \\
\hline Under 25 & 8 & 3.8 & $10-12$ & 81 & 38.4 \\
\hline $26-35$ & 62 & 29.4 & $12-16$ & 53 & 25.1 \\
\hline $36-45$ & 54 & 25.6 & $>16$ & 13 & 6.2 \\
\hline $46-55$ & 39 & 18.5 & Gross family income (MVND) & & \\
\hline $56-65$ & 31 & 14.7 & $<50$ & 3 & 1.4 \\
\hline Over 65 & 17 & 8.0 & $50-100$ & 27 & 12.8 \\
\hline$\underline{\text { Ratio male to female }}$ & & & $100-200$ & 73 & 34.6 \\
\hline 0 (no male) & 4 & 1.9 & $200-350$ & 57 & 27.0 \\
\hline 0 - 1 (more female) & 71 & 33.6 & $350-500$ & 43 & 20.4 \\
\hline 1 (male is equal to female) & 78 & 37.0 & $>500$ & 8 & 3.8 \\
\hline >1 (more male) & 58 & 27.5 & & & \\
\hline
\end{tabular}

Hanoi University of Science, was formed to test the questionnaire in terms of reliability and validity. All members of the focus group were asked every question in the questionnaire. The questionnaire was then revised and completed until it was well understood by the entire focus group. We acknowledge that the composition of this focus group was not ideal for testing a general public survey, but the focus group testing did result in substantial improvements to the clarity of the questionnaire. The questionnaire was designed to gather information on WTP for PFR. Specifically, lists of values on the payment card questionnaire were: 0 VND, 5 thousand VND, 10 thousand VND, 20 thousand VND, 40 thousand VND, 50 thousand VND, 100 thousand VND, 150 thousand VND, 200 thousand VND, and 250 thousand VND. The respondent was asked to select the highest amount that they would still vote for the project of forest restoration in the upland (Box 1). Face-to-face interviews were conducted at the respondent's home during the day time. When interviewing, only the respondent was asked and others were not allowed to contribute to the interview. This condition was maintained to avoid bias.

In order to determine the factors influencing the magnitude of WTP for forest restoration, the survey team gather the relevant information group, including: (1) characteristics of respondents such as age, sex, education; (2) characteristics of the household livelihood like income, gender structure; (3) their opinion on payment for environmental service, and (4) their evaluation on household's monthly payment for electricity consumption.

\section{Results}

\subsection{Willingness-to-Pay Responses}

A total of 211 respondents agreed to answer the questionnaire among 220 households that were contacted, representing a $\sim 96 \%$ response rate. The WTP bid interval was determined by the interval of the bid value circled and the next bid value on the payment card. If the respondent circled bid value of 5 thousand VND, for example, then the bid interval was determined to be between 5 thousand VND and 10 thousand VND. In this survey, among 211 respondents, $57.0 \%$ of them indicated a bid interval of (0; 5 thousand VND), while $45.0 \%$ of the sample had a different bid interval. The weighted average was calculated by taking the midpoint of the bid interval times the percentage of the respondent picking each bid value. The total weighted average of WTP was 23.84 thousand VND (Table 2). 
Box 1. Payment card question format.

\begin{tabular}{|c|c|c|c|}
\hline \multicolumn{4}{|c|}{$\begin{array}{l}\text { If passage of the proposal would cost you some amount of money every year for the foreseeable future, } \\
\text { what is the highest amount that you would pay monthly and still vote for the forest restoration program? } \\
\text { (CIRCLE THE HIGHEST AMOUNT THAT YOU WOULD STILL VOTE FOR } \\
\text { THE PROJECT OF FOREST RESTORATION IN THE UPLAND) } \\
\text { Associated payment card was: }\end{array}$} \\
\hline 0 & 5 & 10 & 20 \\
\hline 40 & 50 & $\square 100$ & 150 \\
\hline 200 & 250 & $\square>250$ & (Unit: 1000 VND) \\
\hline
\end{tabular}

Table 2. Willingness-to-pay bid levels on the payment card and it is presented in interval value, the weighted average is calculated by multiplying the average of willingness-to-pay and the percentage of response rate.

\begin{tabular}{ccccc}
\hline WTP bid (Thousand VND) & Interval (Thousand VND) & Average & $\mathbf{( \% )}$ & Weight Average (Thousand VND) \\
\hline 0 & $0-5$ & 2.5 & 57.0 & 1.42 \\
5 & $5-10$ & 7.5 & 9.0 & 0.68 \\
10 & $10-20$ & 15 & 4.3 & 0.65 \\
20 & $20-40$ & 30 & 10.4 & 3.12 \\
40 & $40-50$ & 45 & 1.4 & 0.63 \\
50 & $50-100$ & 75 & 11.8 & 6.85 \\
100 & $100-150$ & 125 & 5.2 & 0.50 \\
150 & $150-200$ & 175 & 0.5 & 1.13 \\
200 & $200-250$ & 225 & 0.5 & 0.00 \\
250 & $250-300$ & 275 & 0.0 & 23.84 \\
\hline
\end{tabular}

\subsection{Willingness-to-Pay Estimation}

WTP was estimated using MLE models (Table 3 and Table 4). Median WTP was 6,276.17 VND with a mean of WTP of 37,830.51 VND. This indicates that the average respondent is willing to pay 37,830.51VND for forest restoration. The five significant independent variables were Edu, Rationmf, Lnincome, Fpayelect, and Votepes. Specifically, Votepes was considered the strongest factor in the model with confident level at $99 \%$, it was followed by Ratiomf and Edu with confident level at 95\%, and lastly Fpayelect and Lnincome with confident level at $90 \%$. The coefficient of variable of Votepes was positive (2.5345), indicating that if the respondent agreed to support payment for environmental service (PES), then they tended to be willing to pay for forest restoration. This implies that higher or better awareness of PES, was associated with a higher WTP for forest restoration. The coefficient of ratiomf was negative $(-0.4242)$, indicating that a higher ratio of females to males in the household was associated with a greater WTP for forest restoration. The coefficient of Edu was positive (0.0706), suggesting that more education was associated with a higher WTP for forest restoration. The coefficient of Lnincome was positive (0.4734) indicating that higher household income was associated with a greater WTP for forest restoration. Lastly, the coefficient of variable of Fpayelect was positive (0.3745), so it does reflect that if the respondent feels that current payment for water and electricity is high then they tend to be willing to pay for forest restoration.

\section{Discussion}

There are two possible issues associated with WTP estimation in terms of understating and overstating a bid value (Alhassan, 2012). The first issue occurs due to a "zero" response, which may be protest bids. The second 
Table 3. Lists of variables in the maximum likelihood estimator model.

\begin{tabular}{|c|c|c|c|c|c|}
\hline Variable & Definition & Mean & Std. Dev. & Min & Max \\
\hline Edu & Years of education (numbers) & 10.97 & 4.80 & 0 & 20 \\
\hline Ratiomf & Ratio of male to female & 1.22 & 0.75 & 0 & 4 \\
\hline Lnlncome & Logarithm of gross income (thousand VND) & 19.079 & 0.617 & 17.3990 & 20.7233 \\
\hline Fpayelect & $\begin{array}{l}\text { Feel that the paid money for electricity households' } \\
\text { consumption monthly is } \\
\text { (very much }=5 \text {; much }=4 \text {; normal }=3 \text {; little }=2 \text {; very little }=1 \text { ) }\end{array}$ & 3.29 & 0.73 & 0 & 5 \\
\hline Votepes & $\begin{array}{l}\text { Dummy variable of vote for payment } \\
\text { for environmental services (yes }=1 \text {; no }=0 \text { ) }\end{array}$ & 0.77 & 0.41 & 0 & 1 \\
\hline Wtpl & Lower bound of the WTP interval & 16,327 & 30,372 & 0 & 200,000 \\
\hline Wtpu & Upper bound of WTP interval & 31,279 & 46,020 & 5,000 & 250,000 \\
\hline Midwtp & Midpoint of the WTP interval & 23,803 & 38,042 & 2,500 & 225,000 \\
\hline Lnwtpl & Logarithm of the lower bound of the WTP interval & 4.339 & 5.042 & 0 & 12.206 \\
\hline Lnwtpu & Logarithm of the upper bound of WTP interval & 9.45 & 1.25 & 8.51 & 12.42 \\
\hline Lnmidwtp & Logarithm of the midpoint of WTP interval & 8.94 & 1.45 & 7.8240 & 13.3847 \\
\hline
\end{tabular}

Table 4. MLE model to estimate willingness-to-pay value.

\begin{tabular}{ccccccc}
\hline Variables & Coefficient & Std. Err. & $\mathbf{Z}$ & $\boldsymbol{P}>|\mathbf{z}|$ & [95\% Conf. & Interval] \\
\hline Cons & -4.3049 & 4.874 & 2.06 & 0.377 & -13.8579 & 5.2481 \\
Edu & 0.0706 & 0.034 & -2.00 & 0.039 & 0.00351 & 0.1378 \\
Ratiomf & -0.4242 & 0.212 & 1.90 & 0.045 & -0.8394 & -0.0089 \\
Lnincome & 0.4734 & 0.249 & 1.77 & 0.058 & -0.0151 & 0.9620 \\
Fpayelect & 0.3745 & 0.211 & 5.07 & 0.076 & -0.0396 & 0.7886 \\
Votepes & 2.5345 & 0.499 & -0.88 & 0.000 & 1.5548 & 3.5152 \\
$\sigma$ & 1.8954 & & & & & \\
Log likelihood & -299.1913 & & & & & \\
Prob $>$ chi2 & 0.0000 & & & & & \\
Mean WTP & $37,830.51$ VND & & & & & \\
\hline
\end{tabular}

issue appears due to an actual "zero" response when the respondents place a no value on the goods (Boyle, 2003). In our survey, the total percentage of urban residents who were not willing to pay (both protest and actual zeros) was 57.0\% (Table 2). Although both sources of error may have impacted our estimate of mean WTP, we cannot determine if estimated WTP is underestimated or overestimated. To some extent, each error may offset the other, so our WTP estimation is considered valid (Alhassan, 2012). One drawback of the payment card method that we used is that the respondent can pick their own price given the different payment levels, so we often get relatively low estimates on WTP (Blaine et al., 2005).

The MLE models allowed us to estimate WTP for forest restoration. Urban residents in Hanoi were willing to pay around 37,830 VND per household per month for forest restoration, which is higher than what urban residents of Ho Chi Minh, Vietnam were willing to pay (16,510 VND per household) per month for biodiversity conservation in U Minh Thuong National Park (Huynh \& Yabe, 2014). These results indicate that the CVM method in general and MLE model specifically, are efficient for estimating WTP value for forest restoration or other environmental goods and services. 
Our results from the MLE model suggest that WTP for forest restoration depends on social and economic factors of the respondent (Table 4). These results are consistent with the findings from similar studies in Vietnam (Dang, 2007; Do and Bennett, 2007, Huynh and Yabe, 2014). The coefficient of variable of Votepes was 2.5345 in the model, suggesting that the awareness of the respondents regarding the need for forest restoration is positive. This provides policy-makers a reliable foundation to continue to raise awareness as well as knowledge about the environmental role of forests and forest restoration programs. This may be a good approach to access the untapped source of restoration funding from urban residents.

\section{Conclusion}

This study employed a Contingent Valuation Method (CVM) to estimate urban household's willingness-to-pay (WTP) for forest restoration in the upland area of Vietnam. On average, each household was willing to pay 37,830 VND per month through water billing for forest restoration programs. Respondent's WTP for forest restoration was related to their level of education, income, female-to-male ratio in the household, attitude towards monthly household's electricity consumption, and awareness of payment for environmental service. Our findings suggest that either improving households' income and educational level or focusing on females in the family may improve access the untapped source of restoration funding among urban households.

\section{References}

Alhassan, M. (2012). Estimating Farmers' Willingness-to-Pay for Improved Irrigation: An Economic Study of the Bontanga Irrigation Scheme in Northern Ghana. Master Thesis. Fort Collins, CO: Colorado State University.

Bishop, J., \& Landell-Mills, N. (2002). Forest Environmental Services: An Overview. In S. Pagiola, J. Bishop, \& N. LandellMills (Eds.), Selling Forest Environmental Services: Market-Based Mechanisms for Conservation and Development (pp. 15-36). UK \& USA: Taylor \& Francis.

Blaine, T. W., Lichtkoppler, F. R., Jones, K. R., \& Zondag, R. H. (2005). An Assessment of Household Willingness to Pay for Curbside Recycling: A Comparison of Payment Card and Referendum Approaches. Journal of Environmental Management, 76, 15-22.

Boyle, K. J. (2003). Contingent Valuation in Practice. A Primer on Nonmarket Valuation (pp. 111-169). Springer.

Dang, T. T. (2007). Willingness-to-Pay for Conservation of the Vietnamese Rhino. The Economy and Environment Program for Southeast Asia (EEPSEA).

De Jong, W., \& Trieu, V. H. (2006). Forest Rehabilitation in Vietnam: Histories, Realities, and Future: Histories, Realities, and Future. Bogor: Center for International Forestry Research (CIFOR).

Do, N. T., \& Bennett, J. (2007). Willingness-to-Pay for Wetland Improvement in Vietnam's Mekong River Delta. Canberra: Australian Agriculture and Resource Economics Society.

Huynh, V. K., \& Yabe, M. (2014). The Demand of Urban Residents for the Biodiversity Conservation in U Minh Thuong National Park, Vietnam. Agricultural and Food Economics, 2, 1-13. http://www.agrifoodecon.com/content/2/1/10

JICA (2013). Study on Potential Forests and Land Related to Climate Change and Forests in The Socialist Republic of Viet Nam. Hanoi: JICA, 285 p.

Khuc, V. Q. (2013). Household's Willingness-to-Pay Estimation for Safe Drinking Water: A Case Study in Vietnam. Master Thesis. Fort Collins, CO: Colorado State University.

Nguyen, H. N. (2007). Forest Rehabilitation in Vietnam. In: D. K. Lee (Ed.), Keep Asia Green, Volume I “Southeast Asia”, 2007 (pp. 209-242). IUFRO World Series Volume 20-1. Vienna.

Nguyen, Q. T. (2011). Payment for Environmental Services in Vietnam: An Analysis of the Pilot Project in Lam Dong Province. Occasional Paper No. 5. Hanoi: RECOFTC.

Nguyen, T. T., \& Tenhunen, J. (2013). Linking Regional Land Use and Payments for Forest Hydrological Services: A Case Study of Hoa Binh Reservoir in Vietnam. Land Use Policy, 33, 130-140.

http://dx.doi.org/10.1016/j.landusepol.2012.12.015

Pham, T. T., Bennett, K., Vu, T. P., Brunner, J., Le, N. D., \& Nguyen, D. T. (2013). Payments for Forest Environmental Services in Vietnam: From Policy to Practice. Bogor: Center for International Forestry Research (CIFOR).

Reutterer, P. D. T., \& Breidert, C. (2007). Estimation of Willingness-to-Pay: Theory, Measurement, Application. Doctoral Thesis. Welthandelsplatz: Vienna University of Economics and Business.

Sunderlin, W. D., \& Huynh, T. B. (2005). Poverty Alleviation and Forests in Vietnam. Bogor: Center for International Forestry Research (CIFOR). 
To, X. P., Dressler, W. H., Mahanty, S., Pham, T. T., \& Zingerli, C. (2012). The Prospects for Payment for Ecosystem Services (PES) in Vietnam: A Look at Three Payment Schemes. Human Ecology, 40, 237-249. http://dx.doi.org/10.1007/s10745-012-9480-9

Yalfal, T. T., Ayalneh, B., \& Mengistu, K. (2013). Willingness to Pay for Rehabilitation of Degraded Forest: Implications for Community Based Forest Recovery, Management and Forest Policy. Saarbrücken: Lambert Academic Publishing. 